\title{
ANALISIS VEGETASI DAN TINGKAT KESEJAHTERAAN MASYARAKAT PENGELOLA AGROFORESTRI DI DESA SUMBER AGUNG KECAMATAN KEMILING KOTA BANDAR LAMPUNG
}

\section{(VEGETATION ANALYSIS AND PROSPEROUS OF SOCIETY AGROFORESTRY ORGANIZER IN THE SUMBER AGUNG VILLAGE KEMILING DISTRICT BANDAR LAMPUNG)}

\author{
Selviani Tiurmasari, Rudi Hilmanto, dan Susni Herwanti \\ Jurusan Kehutanan Fakultas Pertanian Universitas Lampung, \\ Jl. Soemantri Brojonegoro no. 1 Bandar Lampung \\ E-mail: selviani.pasaribu@gmail.com
}

\begin{abstract}
ABSTRAK
Agroforestri merupakan salah satu bentuk pengelolaan kehutanan yang berkelanjutan secara ekologi, ekonomi dan sosial. Penelitian ini bertujuan untuk mengidentifikasi keanekaragaman jenis tanaman, menentukan pendapatan masyarakat dari agroforestri, dan menganalisis kesejahteraan petani agroforestri berdasarkan vegetasi menggunakan metode Indeks Nilai Penting (INP) dan untuk mengetahui tingkat kesejahteraan petani menggunakan pendekatan pendapatan yang disetarakan dengan harga beras (Sajogyo, 1997). Sebanyak 6 kelompok tani yang diambil sampelnya secara acak di setiap kelompok menggunakan rumus cluster sampling sehingga diperoleh 41 kepala keluarga petani agroforestri. Lahan kelompok tani Tanjung Manis pada fase pohon didominasi oleh pohon durian (INP $=734.08 \%$ ), alpukat $(\mathrm{INP}=398.70 \%)$ dan kakao $(\mathrm{INP}=178.37 \%)$. Lahan kelompok tani Mata Air didominasi oleh kemiri (INP $=61.48 \%$ ) dan karet $($ INP $=361.93 \%)$. Lahan kelompok tani Umbul Kadu didominasi oleh kopi $(\mathrm{INP}=461.123 \%)$, kakao $(\mathrm{INP}=242.24 \%)$ dan durian $(\mathrm{INP}=$ $210.70 \%$ ). Lahan kelompok tani Cirate didominasi oleh melinjo (INP $=193.50 \%$ ) dan karet $(\mathrm{INP}=151.90 \%)$. Kelompok tani Pemancar didominasi oleh jengkol $(\mathrm{INP}=179.93 \%)$, melinjo (INP $=105.59 \%)$ dan durian $(\mathrm{INP}=102,38 \%)$. Lahan kelompok tani Sukawera didominasi oleh alpukat $(\mathrm{INP}=234.57 \%)$ dan karet $(\mathrm{INP}=226.49 \%)$. Kelompok tani Desa Sumber Agung yang memiliki pendapatan tertinggi yaitu kelompok Umbul Kadu $(251,28 \%)$ kemudian Sukawera (20,11\%), Tanjung Manis (16,11\%), Pemancar (14,65\%), Mata Air $(14,18 \%)$ dan yang terendah adalah Cirate $(13,67 \%)$. Tingkat kesejahteraan petani pada gabungan kelompok tani Desa Sumber Agung berada dalam kategori sejahtera sebanyak $66,67 \%$ dan sebanyak 33,33\% dapat dikategorikan belum sejahtera.
\end{abstract}

Kata kunci: analisis vegetasi, keanekaragaman, pendapatan, tingkat kesejahteraan

\section{ABSTRACT}

Agroforestry was a form of sustainable forest management in ecological, economic and social. This research was aimed to identify the diversity of plant species, determining people's income from agroforestry, and analyzing the welfare of agroforestry farmers based on Importance Value Index (IVI) and to determine the level of farmers prosperity using the income approach based the price of rice (Sajogyo, 1997). Six groups of farmers were sampled randomly using cluster sampling formula to obtain 41 heads of agroforestry farming families. The field of Tanjung Manis farmers group in tree phase was dominated by durian tree $(I V I=734,08 \%)$, avocado $(I V I=398,70 \%)$ and cocoa $(I V I=178,37 \%)$. The field of Mata Air farmers group was dominated by candlenut $(I V I=61,48 \%)$ and rubber $(I V I=$ 
361,93\%). The field of Umbul Kadu farmers group was dominated by coffea (INP = $461,12 \%)$, cocoa $(I V I=242,24 \%)$ and durian $(I V I=210,70 \%)$. The field of Cirate farmers group was dominated by melinjo $(I N P=193,50 \%)$ and rubber $(I V I=151,90 \%)$. The field of Pemancar farmers group was dominated by jengkol $(I N P=179$ 93\%), melinjo $(I V I=$ $105,59 \%)$ and durian $(I V I=102,38 \%)$. The field of Sukawera farmers group was dominated by avocado $(I V I)=234,57 \%)$ and rubber $(I V I=226,49 \%)$. The farmers group at Sumber Agung village that has the highest income was Umbul Kadu (21,28\%), Sukawera (20,11\%), Tanjung Manis (16,11\%), Pemancar (14,65\%), Mata Air (14,18\%) and the lowest was Cirate $(13,67 \%)$. The farmers group in Sumber Agung village that have been categorized as prosperous comprising $66,67 \%$ and yet prosperous comprising $33,33 \%$.

Key word: analysis of vegetation, diversity, income, welfare

\section{PENDAHULUAN}

Perkembangan teknologi yang semakin pesat membawa dampak pada berbagai sektor kehidupan yang bersamaan dengan meningkatnya laju pertumbuhan penduduk, hal ini menyebabkan peningkatan jumlah permintaan dalam pemenuhan kebutuhan hidup manusia. Manusia mengadakan eksploitasi secara besar-besaran untuk memenuhi kebutuhan hidupnya sehingga pada sektor kehutanan semakin banyak dikonversi ke non kehutanan (Wijayanti, 2005).

Pembukaan lahan hutan secara besar-besaran dapat menimbulkan banyak kerusakan dan permasalah-permasalahan baru khususnya di kawasan hutan maupun kerusakan pada kondisi lingkungan seperti erosi tanah, banjir, kekeringan, kepunahan ekosistem, dan terjadi perubahan iklim global yang sangat cepat. Salah satu penyebab pembukaan lahan hutan adalah semakin berkurangnya lahan pertanian di Indonesia. Selama periode 1999-2002 telah terjadi pengurangan lahan sawah seluas 563.159 ha sehingga menyebabkan alih guna fungsi lahan hutan menjadi lahan pertanian baru semakin besar.

Salah satu cara untuk mengatasi alih guna lahan dari kondisi sekarang ini adalah dengan melakukan sistem agroforestri yang merupakan salah satu sistem pertanian berkelanjutan dengan menggunakan sebagian lahan hutan sebagai pengganti lahan pertanian tanpa merusak ekosistem dan kondisi lingkungan hutan (Roosita, 2004). Menurut (Sabarnurdin, 2002) pengembangan agroforestri tidak hanya terfokus pada teknik dan biofisik saja akan tetapi kebijakan pemerintah yang dibuat sebagai aturan dalam penggunaan sistem agroforestri juga sangat menentukan perkembangan agroforestri selanjutnya.

Pengembangan dan pengelolaan agroforestri di Tahura Wan Abdul Rachman (Tahura WAR) secara keseluruhan, tidak hanya jenis tanaman yang perlu diperhatikan tetapi juga kondisi vegetasinya sehingga sangatlah diperlukan informasi ekologis yang benar mengenai keberadaan vegetasi yang dapat dilakukan dengan menganalisis struktur vegetasinya. Informasi yang diperlukan adalah komposisi jenis, dominansi, penyebaran maupun asosiasi antara jenis-jenis pohon penyusun vegetasi. Analisis vegetasi merupakan cara yang akan digunakan untuk memperoleh informasi tersebut.

Tahura WAR dibatasi oleh beberapa desa dan salah satunya adalah Desa Sumber Agung di Kecamatan Kemiling Kota Bandar Lampung. Kelompok Tani Pengelola dan Pelestarian Hutan (KPPH) di Desa Sumber Agung terdiri dari 6 kelompok yaitu Cirate, Mata Air, Pemancar, Sukawera, Tanjung Manis, dan Umbul Kadu. Pemanfaatan hutan konservasi yang dilakukan kelompok tani Kelurahan Sumber Agung dengan menanam pohon serbaguna/MPTS (Multi Purpose Trees Species) dengan sistem Agroforestri. Beberapa contoh tanaman MPTS yang ditanam petani di Sumber Agung adalah karet (Hevea 
brasiliensis), durian (Durio zibethinus), kemiri (Aleurites moluccana), coklat (Theobroma cacao), pisang (Musa sp), petai (Parkia speciosa), cengkeh (Eugenia aromatic), tangkil (Gnetum gnemon), bambu (Bambusa), kopi (Coffea robusta), lada (Piper nigrum), cempaka (Michelia champaca), dan aren (Arenga pinnata).

Pola agroforestri yang terus berkembang diharapkan dapat menjaga kelestarian hutan dan peningkatan kesejahteraan masyarakat sehingga diperlukan penelitian ini untuk mengetahui komposisi vegetasi baik pada saat ini maupun dimasa yang akan datang. Hasil penelitian ini diharapkan dapat membantu atau menambah informasi perubahan atau perkembangan jenis-jenis penyusun hutan dan meningkatkan kesejahteraan petani yang mengusahakan pengelolaan agroforestri.

\section{METODE PENELITIAN}

Penelitian dilakukan di Desa Sumber Agung Kecamatan Kemiling Bandar Lampung pada bulan Mei 2015. Objek penelitian yang digunakan adalah petani yang menerapkan agroforestri di Desa Sumber Agung, Kecamatan Kemiling, Kota Bandar Lampung. Alat yang digunakan penelitian ini adalah tally sheet, kuisioner atau daftar pertanyaan, alat tulis, alat hitung, computer dan kamera. Data yang dikumpulkan dalam penelitian ini adalah data primer dan data sekunder. Data primer yang dibutuhkan beberapa karakteristik responden yaitu: pendidikan, pekerjaan, sosial ekonomi, jenis-jenis dan jumlah tanaman yang ditanam pada lahan agroforestri serta pendapatan yang diterima dan biaya yang dikeluarkan dalam pengelolaan agroforestri. Sedangkan data sekunder yang dibutuhkan adalah data umum terdapat di instansi desa, kecamatan dan lembaga-lembaga yang berkaitan dengan penelitian.

\section{A. Metode Pengumpulan Data}

1. Teknik observasi pengamatan secara langsung oleh peneliti untuk mengambil data berdasarkan kondisi tertentu sesuai dengan maksud penelitian. Kondisi tegakan diduga dengan analisis vegetasi dengan menggunakan metode petak tunggal dan menggunakan intensitas sampling $10 \%$ karena luas lokasi penelitian yang kurang dari 1000 ha yaitu sebesar 522,761 ha. Lokasi yang diteliti di Desa Sumber Agung Kawasan Register 19 dibagi menjadi 41 petak dengan total luas lahan yang diteliti sebesar 79,75 ha, dimana dalam setiap petak ukur tersebut dibagi menjadi 4 sub plot dengan ukuran 20x20 m untuk vegetasi tingkat pohon, 10x10 m untuk vegetasi tingkat tiang, $5 \times 5 \mathrm{~m}$ untuk vegetasi tingkat pancang, $2 \times 2 \mathrm{~m}$ untuk vegetasi tingkat semai dan tumbuhan bawah (Lianah, 2013).

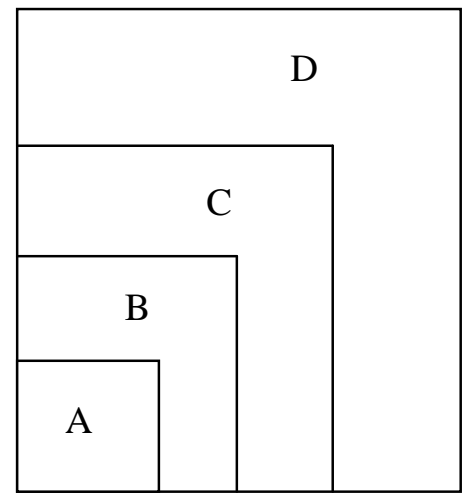

$$
\begin{aligned}
& \text { Keterangan } \\
& \begin{array}{ll}
\mathrm{A}=\text { Vegetasi semai } & =2 \times 2 \mathrm{~m} \\
\mathrm{~B}=\text { Vegetasi pancang } & =5 \times 5 \mathrm{~m} \\
\mathrm{C}=\text { Vegetasi tiang } & =10 \times 10 \mathrm{~m} \\
\mathrm{D}=\text { Vegetasi pohon } & =20 \times 20 \mathrm{~m}
\end{array}
\end{aligned}
$$

Gambar 2. Luas Petak Pengamatan 
Penelitian yang dilaksanakan adalah deskriptif kuantitatif sehingga diperlukan kegiatan analisis vegetasi meliputi Agustina (2008):

1. Menentukan lokasi pengambilan sampel.

2. Menentukan lokasi jalur yang telah disurvey (unit contoh) pada masing-masing lahan yang dikelola petani agroforestri.

3. Membuat petak ukur/plot dilakukan pada lahan yang dikelola dengan ukuran yang telah ditentukan:

4. Mengukur diameter, tinggi serta tajuk untuk tingkat tiang dan pohon. Sedangkan untuk tingkat semai dan pancang hanya menghitung jenis dan jumlah penutupannya.

5. Pengukuran jenis tanaman menggunakan kriteria pertumbuhan yaitu: semai, pancang, tiang, dan pohon.

6. Mencatat data hasil pengukuran ke dalam tabel pengamatan.

2. Teknik wawancara: data dikumpulkan melalui tanya jawab yang dilakukan langsung terhadap responden dengan menggunakan kuesioner.

3. Studi pustaka: pengumpulan data dilakukan dengan mengumpulkan berbagai data penunjang penelitian yang diperoleh dari studi literatur dan instansi-instansi terkait dengan penelitian ini, yaitu: balai desa atau Kantor Kecamatan Kemiling untuk memperoleh informasi tentang jumlah petani yang mengelola agroforestri dan keadaan lingkungan (profil desa).

\section{B. Pengambilan Sampel Responden}

Berdasarkan dari data sekunder pada tahun 2010 di Desa Sumber Agung terdapat Kelompok Tani Pengelolaan dan Pelestarian Hutan (KKPH) yang terdiri dari 6 kelompok tani, keseluruhan jumlahnya anggotanya 499 kepala keluarga (KK) yang yang mengelola lahan agroforestri (KPPH, 2010).

Sampel yang memenuhi kriteria yang diperlukan dalam penelitian adalah responden yang mengelola agroforestri. Penentuan sampel menggunakan formula Slovin dalam Arikunto (2011), maka didapatkan jumlah responden pada penelitian sebagai berikut:

$$
n=\frac{N}{N(e)^{2}+1}
$$

Keterangan:

$\mathrm{n} \quad=$ jumlah sampel

$\mathrm{N}=$ jumlah populasi

$\mathrm{E}=$ batas eror $15 \%$

1 = bilangan konstan

Maka,

$$
n=\frac{49 y}{499(15 \%)^{2}+1}=40,81 \approx 41
$$

Sedangkan untuk pengambilan sampel pada satuan lahan menggunakan rumus cluster sampling (Walpole, 1995) sebagai berikut :

$\mathrm{Nh}=\frac{\mathrm{Ni}}{\mathrm{N}} \times \mathrm{I}$

Keterangan :

$\mathrm{Nh}$ = banyaknya responden yang dibutuhkan dari setiap kelompok

$\mathrm{Ni}$ = banyaknya sub populasi dari setiap kelompok

$\mathrm{N}$ = jumlah responden yang mewakili populasi

$\mathrm{N}=$ jumlah keseluruhan populasi 
Tabel 1. Jumlah responden anggota KPPH Sumber Agung.

\begin{tabular}{llrr}
\hline No & Nama Kelompok & $\begin{array}{r}\text { Jumlah anggtota } \\
\text { (orang KK) }\end{array}$ & $\begin{array}{r}\text { Jumlah responden (orang } \\
\text { KK) }\end{array}$ \\
\hline 1 & Tanjung Manis & 138 & 11 \\
2 & Sukawera & 82 & 7 \\
3 & Umbul Kadu & 103 & 9 \\
4 & Pemancar & 66 & 5 \\
5 & Mata Air & 54 & 4 \\
6 & Cirate & 56 & 5 \\
\hline & Jumlah & $\mathbf{4 9 9}$ & $\mathbf{4 1}$ \\
\hline
\end{tabular}

Sumber : Data sekunder (KPPH 2010).

\section{Analisis Data}

\section{Analisis Vegetasi}

Pengukuran parameter-parameter vegetasi pada analisis vegetasi dinilai berdasarkan analisa sebagai berikut Kusmana (1997) dalam Indriyanto (2006) meliputi: Kerapatan (K), Kerapatan Relatif (KR), Frekuensi (F), Frekuensi Relatif (FR), luas penutupan tajuk (CR), dan Indeks Nilai Penting (INP).

\section{Analisis Pendapatan dan Tingkat Kesejahteraan Masyarakat}

\section{Analisis Pendapatan}

Analisis kuantitatif digunakan untuk mengetahui tingkat pendapatan petani agroforestri. Pendapatan diperoleh dengan menghitung selisih antara penerimaan yang diterima dari hasil usaha dengan biaya produksi yang dikeluarkan dalam satu tahun, dirumuskan sebagai berikut (Soekartawi, 2002):

$$
\text { u }=\text { Y.Py }-\Sigma \mathbf{X i} \cdot \mathbf{P x i}-\mathbf{B} \mathbf{T} \mathbf{T}
$$

Dimana,

$$
\begin{array}{ll}
\pi & =\text { Pendapatan }(\mathrm{Rp}) \\
\mathrm{Y} & =\text { Produksi }(\mathrm{Kg}) \\
\mathrm{Py} & =\text { Harga hasil produksi }(\mathrm{Rp} / \mathrm{Kg}) \\
\mathrm{Xi} & =\text { Jumlah faktor produksi ke I }(1,2,3, \ldots . \mathrm{n}) \\
\mathrm{PX} & =\text { Harga produksi ke I }(\mathrm{Rp}) \\
\mathrm{BTT} & =\text { Biaya tidak tetap }(\mathrm{Rp})
\end{array}
$$

\section{Analisis Tingkat Kesejahteraan Rumah Tangga Setara Beras}

Analisis tingkat pendapatan responden tiap rumah tangga per tahun adalah total pengeluaran rumah tangga petani, baik pendapatan untuk pangan maupun non pangan. Jika pendapatan dalam setahun dibagi jumlah tanggungan rumah tangga, maka dapat diketahui tingkat pendapatan per kapita per tahun rumah tangga petani. Pendapatan tersebut akan yang disetarakan dengan besarnya pengeluaran per kapita per tahun kemudian dikonversikan kedalam ukuran setara beras, dihitung dalam satuan kilogram, dengan tujuan untuk mengetahui tingkat kemiskinan rumah tangga petani (Sajogyo, 1997). Rata-rata harga beras yang dikonsumsi rumah tangga petani di Kelurahan Sumber Agung saat dilakukan penelitian yaitu sebesar Rp 11.000,00/kilogram. 
1) Paling miskin, apabila pengeluaran/kapita/tahun lebih rendah dari $180 \mathrm{~kg}$ setara nilai beras/tahun.

2) Miskin sekali, apabila pengeluaran/kapita/tahun antara 181-240 kg setara nilai beras/tahun.

3) Miskin, apabila pengeluaran/kapita/tahun antara 241-320 kg setara nilai beras/tahun.

4) Nyaris miskin, apabila pengeluaran/kapita/tahun 321-480 kg setara nilai beras/tahun.

5) Cukup, apabila pengeluaran/kapita/tahun $481-960 \mathrm{~kg}$ setara nilai beras/tahun.

6) Hidup layak, apabila pengeluaran/kapita/tahun lebih tinggi dari $960 \mathrm{~kg}$ setara nilai beras/tahun.

\section{HASIL DAN PEMBAHASAN}

\section{A. Deskripsi Tanaman Pada Sistem Agroforestri di Sumber Agung}

Pada pengambilan sampel dengan metode petak, terdapat perbedaan jumlah jenis pohon dari tiap fase pertumbuhannya. Pada fase semai terdapat 22 jenis, di fase pancang terdapat 9 jenis, di fase tiang terdapat 12 jenis dan di fase pohon dewasa terdapat 13 jenis.

Berdasarkan hasil penelitian tanaman yang ditemukan pada fase semai, pancang, tiang dan pohon dewasa beranekaragam seperti kakao (Theobroma cacao), kopi (Coffea robusta), karet (Hevea brasiliensis), alpukat (Persea Americana), durian (Durio zibethinus), jengkol (Pithecellobium lobatum), melinjo (Gnetum gnemon), rumputan (Poaceae), rumputan (Cychas rumphii), pakisan (Cychas rumphii), dan rumput Teki (Cyperus rotundus). Menurut Agustina (2008), tanaman yang ditemukan pada suatu fase pertumbuhan pohon seperti semai, pancang, tiang dan pohon dewasa akan mencirikan suatu komunitas tumbuhan di wilayah tersebut.

Setiap jenis tanaman memiliki tingkat dominansi yang berbeda. Semakin tinggi tingkat dominansi menunjukkan bahwa nilai INP jenis tanaman yang semakin tinggi. Berdasarkan hasil penelitian tanaman yang mendominasi disetiap kelompok tani yaitu: durian, karet, kopi, melinjo, jengkol, dan alpukat (Tabel 12). Hal ini sesuai dengan pendapat Asmayannur (2012) yang menyatakan bahwa Indeks Nilai Penting adalah angka yang menggambarkan tingkat penguasaan suatu jenis dalam vegetasi. Semakin besar nilai dominansi suatu jenis, maka semakin besar pula peranan jenis tersebut dalam komunitas atau tanaman yang lebih banyak ditanam oleh petani. 
Tabel 2. INP pada fase pohon kelompok tani Desa Sumber Agung.

\begin{tabular}{|c|c|c|c|c|c|c|c|}
\hline $\mathbf{N}$ & \multirow{2}{*}{$\begin{array}{l}\text { Kelompok } \\
\text { Tani }\end{array}$} & \multirow[t]{2}{*}{ Tanaman } & \multicolumn{4}{|c|}{ Fase Pohon } & \multirow{2}{*}{$\begin{array}{c}\text { Produksi } \\
\text { (satuan) }\end{array}$} \\
\hline & & & KR $(\%)$ & FR $(\%)$ & CR $(\%)$ & INP (\%) & \\
\hline \multirow[t]{3}{*}{1} & Cirate & Melinjo & 65,00 & 65,00 & 63,50 & 193,50 & $870 \mathrm{Kg}$ \\
\hline & & Karet & 75,00 & 75,00 & 1,90 & 151,90 & $1.530 \mathrm{Kg}$ \\
\hline & & Total & 140,00 & 140,00 & 65,40 & 345,40 & \\
\hline \multirow[t]{3}{*}{2} & Mata Air & Kemiri & 20,00 & 20,00 & 21,48 & 61,48 & $1.940 \mathrm{Kg}$ \\
\hline & & Karet & 120,00 & 120,00 & 121,93 & 361,93 & $849 \mathrm{Kg}$ \\
\hline & & Total & 140,00 & 140,00 & 143,41 & 423,41 & \\
\hline \multirow[t]{4}{*}{3} & Pemancar & Jengkol & 60,00 & 60,00 & 59,93 & 179,93 & $385 \mathrm{Kg}$ \\
\hline & & Melinjo & 50,00 & 50,00 & 5,59 & 105,59 & $1.025 \mathrm{Kg}$ \\
\hline & & Durian & 36,30 & 36,30 & 29,78 & 102,38 & 1.530 Gandeng \\
\hline & & Total & 146,30 & 146,30 & 95,30 & 387,90 & \\
\hline \multirow[t]{3}{*}{4} & Sukawera & Alpukat & 74,99 & 74,99 & 84,57 & 234,57 & $825 \mathrm{Kg}$ \\
\hline & & Karet & 81,60 & 81,60 & 63,30 & 226,49 & $740 \mathrm{Kg}$ \\
\hline & & Total & 156,59 & 156,59 & 147,87 & 461,05 & \\
\hline \multirow[t]{4}{*}{5} & Tanjung & Durian & 328,33 & 321,22 & 77,41 & 734,08 & 375 Gandeng \\
\hline & Manis & Alpukat & 146.95 & 146.95 & 104,79 & 398,70 & $775 \mathrm{Kg}$ \\
\hline & & Kakao & 56,32 & 56,32 & 65,74 & 178,37 & $6.302 \mathrm{Kg}$ \\
\hline & & Total & 531,60 & 524,49 & 247,95 & $1.311,15$ & \\
\hline \multirow[t]{4}{*}{6} & Umbul & Kopi & 149,99 & 149,99 & 161,12 & 461,12 & $2.970 \mathrm{Kg}$ \\
\hline & Kadu & Kakao & 86,67 & 86,67 & 68,91 & 242,24 & $4.080 \mathrm{Kg}$ \\
\hline & & Durian & 70,45 & 70,45 & 69,79 & 210,70 & 1.050 Gandeng \\
\hline & & Total & 307,12 & 307,12 & 299,82 & 914,06 & \\
\hline
\end{tabular}

Sumber: Data primer (2015).

Pendapatan yang disumbangkan dari pengelolaan agroforestri dideskripsikan oleh tanaman yang ada pada lahan petani melalui nilai INP, KR, FR dan CR yang dapat menjelaskan tingkat dominansi tanaman dan disesuaikan juga dengan jumlah produksinya. Tanaman dengan jumlah produksi yang besar dapat memberikan kontribusi yang banyak terhadap pendapatan petani karena lebih berproduktif dan dapat meningkatkan pendapatan petani.

\section{B. Pola Agroforestri}

Pola agroforestri di Desa Sumber Agung dapat diklasifikasikan dalam pola agrisilvikultur. Sardjono, $d k k$ (2003) mengatakan bahwa agrisilvikultur adalah sistem agroforestri yang mengkombinasikan komponen kehutanan (tanaman berkayu atau woody plants) dengan komponen pertanian (tanaman non-kayu). Pola agrisilvikultur di desa Sumber Agung terdapat komponen tanaman kehutanan dengan komponen tanaman pertanian. Kombinasi pada pola ini meliputi komponen kehutanan seperti dadap, trembesi, sonokeling, dan bayur serta komponen pertanian seperti cabai, kakao, alpukat, kopi, pisang, durian dan melinjo.

Pada agroforestri, jarak tanam umumnya tidak teratur, jumlah pohon setiap jenis bervariasi, demikian juga dalam satu jenis dijumpai variasi umur yang berbeda, sehingga terdapat variasi pemanenan antara masing-masing tanaman agroforestri yang juga menyebabkan perbedaan waktu dalam memperoleh penghasilan dari produk agroforestri. Hal ini sejalan dengan pernyataan Widiarti dan Prajadinata (2008) yaitu pola agroforestri memberikan penghasilan yang bervariasi yakni bersifat rutin, harian, mingguan, bulanan, musiman dan tahunan sehingga agroforestri memberikan hasil secara berkelanjutan bagi para petani.

Tanaman kehutanan tidak banyak memberikan kontribusi terhadap pendapatan agroforestri karena petani menanam tanaman kehutanan sebagai naungan atau tanaman pagar. 
Petani yang menebang pohon tidak untuk dijual namun untuk memenuhi kebutuhan sendiri. Sejalan dengan hasil penelitian Sanudin dan Priambodo (2013) yang menyatakan bahwa penerapan sistem agroforestri diperoleh kontinyuitas pendapatan dimana tanaman semusim dan perkebunan digunakan untuk memenuhi kebutuhan sehari-hari. Sedangkan pendapatan dari kayu selain bisa digunakan untuk kebutuhan sehari-hari juga untuk memenuhi kebutuhan yang sifatnya temporal.

Jenis tanaman yang mendominasi di lahan petani adalah tanaman kopi dan kakao. Tingginya nilai INP kedua tanaman tersebut menunjukkan bahwa setiap lahan agroforestri yang dikelola oleh KPPH terdapat tanaman kopi dan kakao bahkan campuran. Kakao dan kopi merupakan tanaman perkebunan yang banyak ditanam oleh petani karena merupakan tanaman unggulan dan besarnya permintaan, sehinngga dapat meningkatkan pendapatan petani bila dibandingkan dengan tanaman agroforestri lainnya.

Anggota kelompok tani yang banyak didominasi oleh tanaman kopi dapat digolongan kedalam pola agroforestri berbasis kopi ada 11 petani, anggota kelompok tani yang banyak didominasi oleh tanaman kakao dapat digolongkan kedalam pola agroforestri berbasis kakao sebanyak 17 petani dan anggota kelompok tani yang didominasi oleh kedua tanaman (campuran) dapat digolongkan kedalam pola agroforestri campuran sebanyak 13 petani.

Masyarakat umumnya juga menanam jenis buah-buahan di lahan agroforestri seperti durian dan alpukat karena banyak manfaatnya yaitu bisa dikonsumsi pribadi dan menambah pendapatan petani. Masyarakat desa Sumber Agung umumnya menanam buah durian dan alpukat diantara tanaman berkayu (tanaman kehutanan). Seperti pada penelitian Nurrochmat (2005) yang menyatakan bahwa umumnya bentuk pengusahaan lahan masyarakat adalah agroforestri dan kebun campuran dimana tanaman yang memberikan pendapatan yang berarti adalah kelompok buah-buahan.

\section{Kontribusi Produk Agroforestri Terhadap Pendapatan Rumah Tangga}

Sumberdaya hutan khususnya pada pengelolaan agroforestri mempunyai nilai sumberdaya yang sangat tinggi. Sejalan dengan itu, Nurfatriani (2006) mengatakan bahwa nilai sumberdaya hutan sendiri bersumber dari berbagai manfaat yang diperoleh masyarakat. Dengan demikian dapat dikatakan bahwa agroforestri merupakan sumber pendapatan bagi masyarakat Desa Sumber Agung karena hampir seluruh masyarakat setempat mengelola dan memanfaatkan agroforestri.

Masyarakat di Desa Sumber Agung memiliki beranekaagam profesi, namun semua responden memiliki lahan agroforestri sehingga masyarakat memperoleh pendapatan dari pengelolaan agroforestri. Hasil penelitian menunjukkan bahwa pendapatan masyarakat dari pengelolaan hasil agroforestri mencapai Rp 1.005.276.500 per tahun dengan rata-rata sebesar Rp 24.518.939,02 per KK per tahun.

Tabel 3. Pendapatan per tahun kelompok petani Desa Sumber Agung.

\begin{tabular}{llrr}
\hline No & Kelompok tani & Pendapatan Agroforestri & Persentase (\%) \\
\hline 1 & Cirate & 142.153 .000 & 14,14 \\
2 & Mata Air & 146.063 .250 & 14,54 \\
3 & Pemancar & 143.362 .500 & 14,26 \\
4 & Sukawera & 200.491 .500 & 19,94 \\
5 & Tanjung Manis & 170.634 .250 & 16,97 \\
6 & Umbul Kadu & 202.572 .000 & 20,15 \\
\hline \multicolumn{2}{l}{ Total pendapatan petani responden } & $\mathbf{1 . 0 0 5 . 2 7 6 . 5 0 0}$ & $\mathbf{1 0 0 , 0 0}$ \\
\hline
\end{tabular}

Sumber: Data Primer (2015). 
Berdasarkan persentase pada tabel 13 dari total pendapatan pada masing-masing kelompok yaitu: kelompok tani Cirate (14,14\%), Mata Air (14,54\%), Pemancar (14,26\%), Sukawera (19,94\%), Tanjung Manis (16,97\%), dan Umbul Kadu (20,15\%).

Kelompok tani Umbul Kadu memiliki pendapatan paling tinggi yang diperoleh petani dari hasil produksi 3 jenis tanaman agroforestri yang produktif seperti kopi, kakao dan durian, dengan total INP sebesar 914,06\% serta didukung oleh tanaman lainnya seperti kemiri, melinjo dan karet (lampiran tabel 18). Sebaliknya kelompok tani Cirate memiliki pendapatan paling rendah yang diperoleh petani dari hasil produksi 2 jenis tanaman agroforestri yang produktif seperti melinjo dan karet dengan total INP sebesar 345,40\% serta didukung oleh tanaman lainnya seperti kemiri, karet, alpukat, kakao dan kopi (lampiran tabel 18). Pendapatan yang diperoleh petani memang tidak dipengaruhi oleh nilai INP setiap jenis tanaman namun dipengaruhi oleh beberapa faktor seperti jumlah produksi, jenis tanaman yang sudah berproduktif, dan harga jual per satuan jenis komoditi.

\section{Tingkat Kesejahteraan Petani Berdasarkan Kriteria Miskin Sayogyo 1997}

Berdasarkan kriteria Sajogyo (1997), tingkat kemiskinan diukur dengan menggunakan konsep pendapatan per kapita per tahun yang diukur dengan menggunakan standar harga beras per kilogram di tempat pada waktu penelitian. Rata-rata harga beras yang dikonsumsi rumah tangga petani responden sebesar Rp 11.000/kg. Analisis tingkat kesejahteraan rumah tangga anggota kelompok tani berdasarkan pendapatan total menurut Sajogyo (1997).

Menurut hasil perhitungan pada tabel 4 menunjukkan bahwa setiap kelompok tani berada dalam tingkat kesejahteraan yang berbeda-beda. Kategori miskin dan nyaris miskin dapat diasumsikan bahwa petani responden dianggap petani yang belum sejahtera. Sedangkan yang berada dalam kategori cukup dan hidup layak dianggap sejahtera.

Kelompok tani Cirate mempunyai 2 kelompok tani yang sejahtera dan 3 kelompok tani belum sejahtera. Kelompok tani Mata Air mempunyai 4 kelompok tani yang sejahtera. Kelompok tani Pemancar mempunyai 3 kelompok tani yang sejahtera dan 2 kelompok tani belum sejahtera. Kelompok tani Sukawera mempunyai 4 kelompok tani yang sejahtera dan 3 kelompok tani belum sejahtera. Kelompok tani Tanjung Manis mempunyai 2 kelompok yang sejahtera dan 9 kelompok tani belum sejahtera. Kelompok tani Umbul Kadu mempunyai 2 kelompok tani yang sejahtera dan 7 kelompok tani belum sejahtera.

Secara keseluruhan jumlah kelompok tani yang tergolong sejahtera sebanyak 17 kelompok tani $(41,46 \%)$ sedangkan yang belum sejahtera sebanyak 24 kelompok tani $(58,54 \%)$. Selain jumlah pendapatan, tingkat kesejateraan petani dipengaruhi oleh tingkat pendidikan, jumlah tanggungan keluarga, dan luas lahan yang dikelola. Tinggi dan rendahnya tingkat pendidikan tersebut akan mempengaruhi responden dalam mengelola lahan. Ayu (2014) dalam pembahasannya mengatakan bahwa semakin tinggi tingkat pendidikan, maka lahan yang dikelola semakin baik, hal tersebut pada dasarnya berkaitan dengan kemampuan berpikir.

Banyaknya jumlah tanggungan keluarga mempengaruhi tenaga kerja yang dibutuhkan dan jumlah pengeluaran. Menurut Ayu (2014) anggota keluarga yang dimiliki petani dapat dimanfaatkan sebagai tenaga kerja, sehingga jumlah tanggungan keluarga dapat mamacu petani untuk meningkatkan hasil usaha tani. Selain itu, rumah tangga petani yang umumnya sangat terbatas kemampuanya dari segi modal, peran tenaga kerja keluarga sangat menentukan.

Besar atau kecilnya luasan lahan mempengaruhi jumlah produksi dan pendapatan petani. Phahlevi (2013) mengatakan luas lahan pertanian akan mempengaruhi skala usaha yang pada akhirnya akan mempengaruhi efisien atau tidaknya pengelolaan. Sering kali dijumpai semakin luas lahan yang dipakai dalam usaha pertanian semakin tidak efisien lahan 
tersebut, hal ini terbukti dengan adanya responden yang memperoleh pendapatan tinggi, pada luas pengusaahan lahan agroforetri yang berukuran sempit. Hasil penelitian menunjukan bahwa salah satu faktor yang mempengaruhi responden berlahan sempit memperoleh pendapatan tinggi karena jenis tanaman yang diusahakan lebih beragam walaupun dengan jumlah tidak banyak karena menyesuaikan dengan luas lahan, hal inilah yang menyebabkan pendapatan responden tersebut meningkat.

Kriteria kesejahteraan petani responden diketahui berdasarkan tingkat pendapatan responden tiap rumah tangga per tahun dari pendapatan agroforestri. Kualitas hidup petani agroforestri di Desa Sumber Agung secara keseluruhan tergolong kurang dari cukup (belum sejahtera). Hal ini menunjukkan bahwa pengelolaan agroforestri belum banyak memberikan kontribusi terhadap pendapatan petani.

Tabel 4. Kriteria miskin Sajogyo (1997) berdasarkan pendapatan per kapita per tahun setara harga beras anggota kelompok tani Desa Sumber Agung.

\begin{tabular}{|c|c|c|c|c|c|c|}
\hline \multirow[t]{2}{*}{ No } & \multirow[t]{2}{*}{ Kelompok } & \multirow[t]{2}{*}{ Kategori } & \multirow{2}{*}{$\begin{array}{r}\text { Konsumsi } \\
\text { Setara Beras } \\
(\text { Kg/Jiwa) }\end{array}$} & \multicolumn{2}{|c|}{ Jumlah } & \multirow{2}{*}{$\begin{array}{r}\text { Rata-rata Konsumsi } \\
\text { Setara Beras } \\
(\mathrm{Kg} / \mathrm{Jiwa})\end{array}$} \\
\hline & & & & (orang) & $(\%)$ & \\
\hline 1 & T. Manis & Paling miskin & $<180$ & 2 & 18,18 & 129,58 \\
\hline 2 & & Miskin sekali & $181-240$ & 1 & 9,09 & 217,90 \\
\hline 3 & & Miskin & $241-320$ & 4 & 36,36 & 277,75 \\
\hline 4 & & Nyaris miskin & $321-480$ & 2 & 18,18 & 377,41 \\
\hline 5 & & Cukup & $481-960$ & 2 & 18,18 & 588,45 \\
\hline \multirow[t]{2}{*}{6} & & Hidup layak & $>960$ & & & \\
\hline & & Jumlah & & 11 & & 319,98 (Miskin) \\
\hline 1 & Sukawera & Paling miskin & $<180$ & & & \\
\hline 2 & & Miskin sekali & $181-240$ & & & \\
\hline 3 & & Miskin & $241-320$ & & & \\
\hline 4 & & Nyaris miskin & $321-480$ & 2 & 28,57 & 388,36 \\
\hline 5 & & Cukup & $481-960$ & 4 & 57,14 & 729,08 \\
\hline \multirow[t]{2}{*}{6} & & Hidup layak & $>960$ & 1 & 14,29 & 151,74 \\
\hline & & Jumlah & & 7 & & 679,31 (Cukup) \\
\hline 1 & U.Kadu & Paling miskin & $<180$ & 1 & 11,11 & 128,62 \\
\hline 2 & & Miskin sekali & $181-240$ & & & \\
\hline 3 & & Miskin & $241-320$ & 2 & 18,18 & 310,55 \\
\hline 4 & & Nyaris miskin & $321-480$ & 2 & 18,18 & 347,66 \\
\hline 5 & & Cukup & $481-960$ & 4 & 36,36 & 693,27 \\
\hline \multirow[t]{2}{*}{6} & & Hidup layak & $>960$ & & & \\
\hline & & Jumlah & & 9 & & 468,68 (Nyaris Miskin) \\
\hline 1 & Pemancar & Paling miskin & $<180$ & & & \\
\hline 2 & & Miskin sekali & $181-240$ & & & \\
\hline 3 & & Miskin & $241-320$ & 1 & 20 & 261,81 \\
\hline 4 & & Nyaris miskin & $321-480$ & 4 & 80 & 584,16 \\
\hline 5 & & Cukup & $481-960$ & & & \\
\hline \multirow[t]{2}{*}{6} & & Hidup layak & $>960$ & & & \\
\hline & & Jumlah & & 5 & & 519,69 (Cukup) \\
\hline 1 & Mata Air & Paling miskin & $<180$ & & & \\
\hline 2 & & Miskin sekali & $181-240$ & & & \\
\hline 3 & & Miskin & $241-320$ & & & \\
\hline 4 & & Nyaris miskin & $321-480$ & & & \\
\hline 5 & & Cukup & $481-960$ & 3 & 75 & 713 \\
\hline \multirow[t]{2}{*}{6} & & Hidup layak & $>960$ & 1 & 25 & 989,62 \\
\hline & & Jumlah & & 4 & & 782,16 (Cukup) \\
\hline 1 & Cirate & Paling miskin & $<180$ & 1 & 20 & 176,73 \\
\hline 2 & & Miskin sekali & $181-240$ & & & \\
\hline 3 & & Miskin & $241-320$ & & & \\
\hline 4 & & Nyaris miskin & $321-480$ & 2 & 40 & 410,41 \\
\hline 5 & & Cukup & $481-960$ & 1 & 20 & 523,09 \\
\hline \multirow[t]{2}{*}{6} & & Hidup layak & $>960$ & 1 & 20 & $1.033,18$ \\
\hline & & Jumlah & & & & 510,76 (Cukup) \\
\hline
\end{tabular}

Sumber: Data primer (2015). 
Walaupun pengelolaan agroforestri dapat memberikan kontribusi terhadap pendapatan petani, namun berdasarkan kriteria Sajogyo (1997) pendapatan hasil agroforestri belum sepenuhnya dapat mensejahterakan petani. Oleh karena itu perlu pengkayaan jenis tanaman yang dapat meningkatkan pendapatan sebagai nilai tambah kesejahteraan petani.

\section{KESIMPULAN}

Berdasarkan hasil penelitian, dapat diambil kesimpulan sebagai berikut.

1. Jumlah tanaman dilokasi penelitian sebagai berikut: fase semai ada (22 jenis), fase pancang ada (9 jenis), fase tiang ada (12 jenis) dan fase pohon dewasa ada (13 jenis). Tanaman yang mendominasi pada fase pohon yang lebih berproduktif yaitu: durian, alpukat, kakao, kemiri, kopi, melinjo karet dan jengkol,

2. Pendapatan masyarakat dari pengelolaan agroforestri mencapai Rp 1.005.276.500 per tahun dengan rata-rata sebesar Rp 24.518.939,02 per KK per tahun.

3. Hasil analisis diketahui bahwa Kelompok Tani Cirate mempunyai 2 kelompok tani yang sejahtera dan 3 kelompok tani belum sejahtera. Kelompok Tani Mata Air mempunyai 4 kelompok tani yang sejahtera. Kelompok Tani Pemancar mempunyai 3 kelompok tani yang sejahtera dan 2 kelompok tani belum sejahtera. Kelompok Tani Sukawera mempunyai 4 kelompok tani yang sejahtera dan 3 kelompok tani belum sejahtera. Kelompok Tani Tanjung Manis mempunyai 2 kelompok yang sejahtera dan 9 kelompok tani belum sejahtera. Kelompok Tani Umbul Kadu mempunyai 2 kelompok tani yang sejahtera dan 7 kelompok tani belum sejahtera. Secara keseluruhan jumlah kelompok tani yang tergolong sejahtera sebanyak 17 kelompok tani $(41,46 \%)$ sedangkan yang belum sejahtera sebanyak 24 kelompok tani $(58,54 \%)$.

\section{DAFTAR PUSTAKA}

Agustina, D. K. 2008. Studi vegetasi pohon di hutan lindung RPH Donomulyo BKPH Sengguruh KPH Malang. Jurnal Makara Sains. 9(2):9-17.

Asmayannur, I. 2012. Analisis vegetasi dasar di bawah tegakan jati emas (Tectona grandis

L.) dan jati putih (Gmelina arborea Roxb). Jurnal Biologi Indonesia. 1(2):172-177.

Arikunto, S. 2011. Manajemen Penelitian. Buku. Rineka Cipta. Jakarta. 370 p.

Badan Pusat Statistik Provinsi Lampung. 2014. Lampung dalam Angka 2014. Buku. Badan Pusat Statistik Provinsi Lampung. Bandar Lampung. 423 p.

Indriyanto. 2006. Ekologi Hutan. Buku. PT Bumi Aksara. Jakarta. 224 p.

Kelompok Pengelola Pelestari Hutan (KPPH). 2010. Data Perkembangan Anggota Dan Tanaman Kelompok Pengelola Pelestari Hutan (KPPH) Tahun 1998-2010. Buku. KPPH Desa Sumber Agung. Bandar Lampung. 78 p.

Lianah. 2013. Perbandingan analisis vegetasi lingkungan alami Tetrastigma glabratum di Hutan Lindung Gunung Prau sebelum dan sesudah ekploitasi. Prosiding Seminar Nasional Pengelolaan Sumberdaya Alam dan Lingkungan. Jurusan Ilmu Lingkungan Fakultas Biologi Universitas Diponegoro.

Nurfatriani. 2006. Penilaian sumber daya hutan dan lingkungan. Jurnal Ilmu Kehutanan. 29(1):27-36..

Nurrochmat. 2005. Karakteristik hutan rakyat pola kebun campuran. Jurnal Menejemen Hutan Tropika. 31(1):40-45.

Roosita, E. 2004. Pertanian semakin kehilangan daya tariknya. Kompas, 4 Mei 2015, hlm. 3 , kol. 5 . 
Sabarnurdin, M., dan Sambas. 2002. Agroforestry: Konsep, Prospek dan Tantangan. Buku. Universitas Gadjah Mada. Yogyakarta. 44 p.

Sanudin, dan Priambodo, D. 2013. Analisis sistem dalam pengelolaan hutan rakyat agroforestry di Hulu Das Citanduy: kasus di Desa Sukamaju, Ciamis. Jurnal Pertanian Tropik. 1(1):33-46.

Sardjono, M. A., Arifin, H. S., Djogo, T., dan Widjayanto, N. 2003. Klasifikasi dan Pola Kombinasi Komponen Agroforestri. Buku. ICRAF. Bogor: 450 p.

Sajogyo, T. 1997. Garis Kemiskinan dan Kebutuhan Minimum Pangan. Buku. LPSB-IPB. Bogor. $299 \mathrm{p}$.

Soekartawi. 2002. Prinsip Dasar Komunikasi Pertanian. Buku. UI Press. Jakarta. 65 p. Walpole, R. E. 1995. Pengantar Statistik Edisi Ke-4. Buku. PT Gramedia. Jakarta. 579 p. Widiarti, A., dan Prajadinata, S. 2008. Karakteristik Hutan Rakyat Pola Kebun Campuran. Buku. Institut Pertanian Bogor. Bogor. 145 p.

Wijayanti, T. 2005. Analisis finansial tanaman kapuk di Kecamatan Gembong Kabupaten Pati. Jurnal Program Studi Ekonomi Pertanian. 2(2):40—45. 